\title{
In memoriam: Prof. Ignac Fogelman (04.09.1948 - 05.07.2016)
}

\author{
Gopinath Gnanasegaran $^{1}$ - Frédéric Paycha ${ }^{2}$ - Tim Van den Wyngaert ${ }^{3,4}$ • Ora Israel $^{5}$
}

Published online: 26 August 2016

(C) Springer-Verlag Berlin Heidelberg 2016

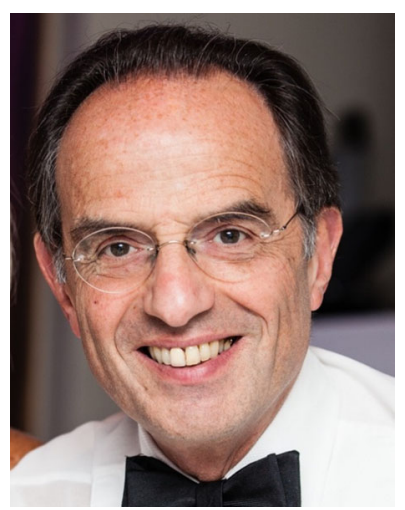

Prof. Ignac Fogelman, "Father of Radionuclide Bone Imaging", passed away on the 5th of July, 2016

Professor Ignac Fogelman was Professor of Nuclear Medicine at King's College London, Honorary Consultant Physician at Guy's and St Thomas' NHS Trust, and Director

Gopinath Gnanasegaran

gopinath.gnanasegaran@nhs.net

1 Department of Nuclear Medicine, Royal Free London NHS Foundation Trust, London, UK

2 Department of Nuclear Medicine, Hôpital Lariboisière, Assistance Publique-Hôpitaux de Paris, Paris, France

3 Department of Nuclear Medicine, Antwerp University Hospital, Edegem, Belgium

4 Faculty of Medicine and Health Sciences, University of Antwerp, Wilrijk, Belgium

5 Department of Nuclear Medicine, Rappaport School of Medicine, Rambam Health Care Campus, Technion, Haifa, Israel of the Osteoporosis Screening and Research Unit, Guy's Hospital, London, UK.

Professor Fogelman was born in 1948, and received his medical training in the Professorial Department of Medicine at the Glasgow Royal Infirmary, where he developed his interest in metabolic bone disease. At that time, Nuclear Medicine in Glasgow came under the wing of the Department of Medicine, and the newly available ${ }^{99 \mathrm{~m}} \mathrm{Tc}-$ diphosphonate imaging agents proved a useful means of investigating metabolic bone disease, leading to the first of over 450 publications between 1977 and 2016, and the completion of his MD. Collectively, his published works represent pioneering contributions to every advance in the field of metabolic bone imaging over 45 years. His seminal research included comparative analyses of the pharmacokinetics and biodistribution of the radiolabelled bisphosphonates used in bone scintigraphy, and the optimization of scan acquisition parameters for bone planar, SPECT, and SPECT-CT. In the early 1970s, he also helped to establish the well-known scintigraphic patterns and gamuts still used today in the differential diagnosis of metastatic disease, miscellaneous metabolic conditions, normal variants, and pitfalls. Later he refined this semiological effort for each main skeletal structure, including the spine, ribs, hand, pelvis, knee, and foot. Another major research interest was the quantification of planar bone scintigraphy, on which he published the first methodological approach in the late 1970s, with later work perfecting and comparing different quantitative methods for the measurement of bone turnover. He envisioned quantification as a universal tool for the assessment of metastatic, metabolic, and rheumatic bone conditions and for monitoring their response to therapy.

He was appointed Consultant Physician in the Nuclear Medicine Department at Guy's Hospital in 1983, which gave further opportunities to develop his interests in bone. He was 
instrumental in starting the first osteoporosis screening service in the UK (1988), and on a broader scope, was pivotal in the introduction of DXA into European clinical practice. In addition, he pioneered the use of (18F)-fluoride positron emission tomography (PET) in the study of regional bone turnover in osteoporosis and other miscellaneous metabolic disorders.

In 1996, Ignac Fogelman, by then a renowned expert in nuclear medicine, became Professor of Nuclear Medicine, and in this position he has supervised at least $17 \mathrm{PhD} / \mathrm{MD}$ students. He was a former board member and trustee of the National Osteoporosis Society and was previously chairman of its Bone Densitometry Forum. Professor Fogelman was Chairman of the Board of Examiners for the MSc in Nuclear Medicine at King's College, London.

Professor Fogelman has written or edited 15 books, all of which have become standard texts in radionuclide bone imaging. His most successful book is the Atlas of Clinical Nuclear Medicine (published now in its third edition), which can be found and is used as a bible in most nuclear medicine departments worldwide. This masterpiece also made him a celebrity in the world of nuclear medicine. His last book in nuclear medicine was Radionuclide and Hybrid Bone Imaging (2012), which he described as the most beautiful project he had been associated with, and he was very happy with a very positive review in EJNMMI, where the reviewers classified it as an absolutely excellent book in skeletal imaging. He has written numerous articles and was guest editor for several volumes in Seminars in Nuclear Medicine. The most memo- rable ones were the two volumes "Skeletal Scintigraphy Update" (2009) and his last project, "Pitfalls and Limitations of Radionuclide and Hybrid Imaging" (2015). It remains an absolute treat to nuclear medicine residents!

In a successful professional life that included innumerable awards and appreciation, a few deserve special mention. The Society of Nuclear Medicine of India awarded him the prestigious Vikram Sarabhai Oration Award in 2005, and in 2014 he was awarded the prestigious Sir Godfrey Hounsfield Memorial Award from the British Institute of Radiology (BIR). He retired from the National Health Service (NHS) in September 2015 after an illustrious career, one which most can only dream of but few can closely match.

His favorite recreations included opera, bridge, theatre, food, wine, music, books, and travel. He had an extraordinary capacity for loyal friendships around the world. Ignac's passing has left a void in the lives of numerous people.

Ignac's lifelong ideals were hard work, passion, and dedication, striving for the highest order of perfection. One of our colleagues in the EANM Bone \& Joint Committee remembers him as the "Father of Radionuclide Bone Imaging", and we believe this is a fitting tribute to a hero. He was always inspiring to many as a teacher, mentor, friend, and colleague. His wise counsel, inspiration, and enthusiasm will be missed by many.

Ignac is survived by his wife Coral, daughter Gayle, son Richard and grandchildren whom he adored. Our deepest condolences and prayers go out to them. 